\title{
Experience with the surgical treatment of coarctation of the aorta in India
}

\author{
W JOHN PERIANAYAGAM, S MURALIDHARAN, P S JAIRAJ, S KRISHNASWAMY, \\ I P SUKUMAR, GEORGE CHERIAN, RUTH MANSFIELD, AND STANLEY JOHN
}

From the Departments of Thoracic and Cardiovascular Surgery, Cardiology, and Anaesthesia, Christian Medical College Hospital, Vellore, India

ABSTRACT Between 1961 and 1977, 51 patients underwent operations for coarctation of the aorta 윽 The average age of presentation of these cases was higher than in other series. Only three were asymptomatic, a finding which is not seen in reports from the West. Operative procedures included ${ }_{\mathbb{D}}$ resection and graft interposition, resection and end-to-end anastomosis, and bypass grafting. $\Phi_{0}$ However, the technique of patch angioplasty, routinely performed in the last three years of this $\frac{\Xi}{\sigma}$ review, seemed by far the most satisfactory procedure. The overall operative mortality was $9 \cdot 8 \% . \stackrel{\Phi}{=}$ Hypertension did not regress in some cases in spite of a successful operation. Recoarctation was not $\vec{\oplus}$ seen in this series. Associated defects influenced results adversely. The overall results of operation ${ }^{\infty}$ for coarctation of the aorta have been very satisfactory and comparable with those in other recorded series.

Between 1961 and 1977, operations for aortic coarctation constituted about $1 \%$ of 6000 cardiac operations at the department of Thoracic and Cardiovascular Surgery, Christian Medical College Hospital, Vellore, India. The aim of this report is to review our experience with these patients with special reference to surgical techniques and results.

\section{Patients and methods}

Fifty-one patients underwent repair of coarctation of aorta. Seventeen of these had additional congenital cardiovascular abnormalities. The youngest was 1 month old and the oldest 48 years of age. The most common age group was between 11 and 20 years (figure). Thirty-five patients were males and 16 were females. Twentyseven patients presented with dyspnoea on exertion, 12 with symptoms of ischaemia of the lower limbs, three with frequent upper respiratory infection, and 16 with symptoms resulting from hypertension. Three were asymptomatic. Forty patients had visible or palpable collateral arteries but rib notching was only evident in 28 . Seven patients had unilateral rib notching suggestive of left subclavian stenosis. An electrocardiogram

Address for reprint requests: Dr WJ Perianayagam, Department of Thoracic and Cardiovascular Surgery, Christian Medical College Hospital, Vellore 632 004, India. revealed left ventricular hypertrophy in $32 \stackrel{\circ}{\circ}$ patients and biventricular hypertrophy in one. $\stackrel{\mathbb{Q}}{2}$ Results were normal in 18 patients. Cardiac $\overrightarrow{\vec{\sigma}}$ catheterisation was carried out in 25 patients to 3 assess the degree of pulmonary hypertension and to document the presence of associated lesions (table). These 25 cases also underwent aortography. The indications were disparity of pulses, 응 unilateral rib notching, atypical features, and $x$ absence of a left subclavian artery shadow.

\section{Surgical treatment}

All subjects underwent surgical correction. In 윽

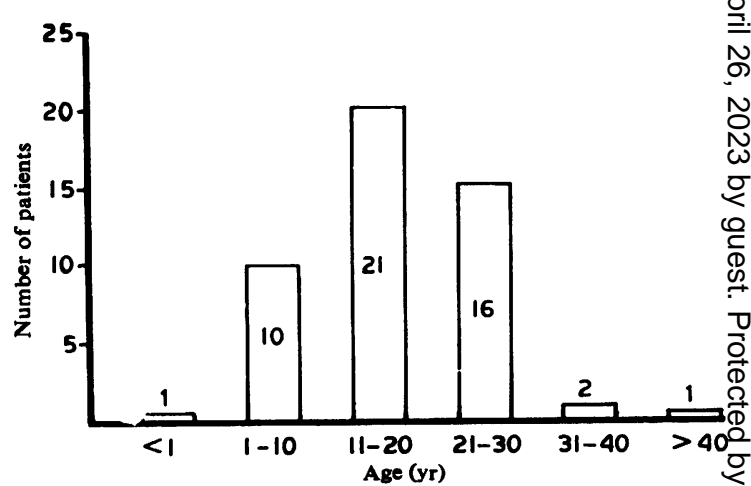

Figure Age distribution of patients 
Table Associated lesions in 25 patients

\begin{tabular}{lc}
\hline Lesions & Number of cases \\
\hline Patent ductus arteriosus & 4 \\
Moderate to severe aortic regurgitation & 3 \\
Ventricular septal defect & 2 \\
Ventricular septal defect and mild aortic regurgitation & 1 \\
Moderate to severe mitral regurgitation & 3 \\
Calcific aortic stenosis and mild mitral regurgitation & 1 \\
Aortic stenosis & 1 \\
Bicuspid aortic valve & 1 \\
Mitral stenosis & 1 \\
\hline
\end{tabular}

those with associated lesions, the operation for coarctation was done first except for two cases with severe aortic stenosis. One had aortic valve replacement three months, and the other open aortic valvotomy six months, before coarctation surgery. Another subject underwent interposition of an aortic graft with concomitant mitral valve replacement. In two others, closure of a ventricular septal defect was carried out two and four years respectively after coarctation surgery.

During operation, halothane was used to induce hypotension in children below 10 years of age. In those above 10 years of age, trimetaphan was used. Sodium nitroprusside has just become available in India and it was used in the last two cases of patch aortoplasty. The duration of aortic clamping was around 60 minutes in those patients who needed resection and grafting early in the series. With the change in technique to patch aortoplasty, the period has been about 30 minutes.

Surgical treatment involved resection and end-to-end anastomosis in 14 cases, resection and interposition of a graft in 21, and bypass grafting in two. However, during the last three years, we have used the technique of patch graft aortoplasty in 14 cases in all age groups.

No patient developed spinal cord or renal damage, or abdominal complications. Five out of 51 patients died. All the deaths occurred in the earlier part of this review; none since 1970. Four of the five patients who died had associated defects. A 22-year-old man who had graft interposition and concomitant mitral valve replacement developed secondary haemorrhage from the suture line on the eighth day after operation and died. A 9-month-old infant who had a large ventricular septal defect had a tracheostomy after the coarctation repair and died on the fifth day from fulminant bronchopneumonia. Two others, one with severe calcific aortic stenosis and mild mitral regurgitation and the other with ventricular septal defect and aortic regurgitation, developed low cardiac output after coarctation repair and died on the fifth and sixth days respectively. One patient died from per- operative overtransfusion.

Recent follow-up data were obtained for all the 46 survivors-follow-up time ranged from three months to 17 years. Symptomatic improvement was seen in all with return of peripheral pulses. Radiological improvement, or regression of left ventricular hypertrophy on the electrocardiogram was seen in all except three cases. Systolic hypertension persisted in seven cases for periods ranging from six months to two and a half years. Three of these patients were reinvestigated, and had no recurrence of coarctation. Clinical signs gave no evidence of recoarctation in the other four.

\section{Discussion}

The average age of presentation of our patients was higher than in other reported series. This was probably responsible for the fact that 48 of the 51 patients were symptomatic, in sharp contrast to the reports from the West. ${ }^{1}$ Operation was accomplished with an acceptable mortality, which was directly related to the incidence of associated congenital heart disease, and is in accordance with other series. ${ }^{2}$ The overall results of operation have been gratifying. The technique of patch angioplasty has several advantages over the conventional techniques. This procedure was first described by Vosschulte in $1961^{3}$ and was later populanised by Moor et $a l^{4}$ and Reul et al. ${ }^{5}$ We have carried on this procedure in 14 patients during the last three years and there have been no recurrences. Even in adults with calcified deposits in the coarctated segment and with large thin-walled collaterals, the technique is applicable.

Seven patients had persistent hypertension despite adequate repair. These patients were above 10 years of age. Maron et $a l^{6}$ reported on the high incidence of residual hypertension that occurred when coarctation repair was performed between 5 and 12 years of age. Nanton and Olley $^{7}$ have shown that the younger the patient at the time of repair, the greater is the reduction in blood pressure. The cause of residual hypertension in the absence of recoarctation is unclear.

\section{References}

1 Perloff JK. The clinical recognition of congenital heart disease. Philadelphia: IVB Saunders Company, 1970: 97.

2 Langford BS, Kidd J, Keith JD. The natural history and progression of treatment of congenital heart defects. Springfield, Illinois: Charles C 
Thomas, 1971.

3 Vosschulte K. Surgical correction of coarctation of the aorta by an "isthmusplastic" operation. Thorax 1961; 16:338-45.

4 Moor GF, Ionescu MI, Ross DN. Surgical repair of coarctation of aorta by patch grafting. Ann Thorac Surg 1972; 14:626-30.

5 Reul GJ, Kabbani SS, Sandiford FM, Wukasch DC, Cooley DA. Repair of coarctation of the thoracic aorta by patch graft aortoplasty. J Thorac Cardiovasc Surg 1974; 68:696-704.

6 Maron BJ, O'Neal HJ, Rowe RD, Mellits ED. Prognosis of surgically corrected coarctation of aorta: a 20 year postoperative appraisal. Circulation 1973; 47:119-26.

7 Nanton MA, Olley PM. Residual hypertension after coarctectomy in children. Am $\mathrm{J}$ Cardiol 1976; 37:769-72. 